Disponível em http://www.anpad.org.br/rac

RAC, Rio de Janeiro, v. 18, n. 3, art. 2, pp. 261-284, Maio/Jun. 2014

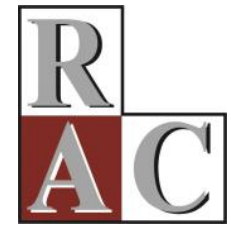

\title{
O Efeito da Sinalização de Qualidade no Contexto de Serviços
}

\author{
The Effect of Signaling Quality in a Service Context
}

Gabriela Solalinde E:mail: gabysolalinde@hotmail.com Empresa Seven's Travel Rua Vicente da Fontoura, 750/309, Santana, 90640-000, Porto Alegre, RS, Brasil.

Cristiane Pizzutti E-mail: crispizzutti@gmail.com Universidade Federal do Rio Grande do Sul - UFRGS Rua Washington Luis, 855, Centro, 90010-460, Porto Alegre, RS, Brasil. 


\title{
Resumo
}

A teoria da sinalização afirma que os sinais são ações que a empresa pode realizar para transmitir informações sobre a qualidade dos seus produtos. Este trabalho busca ampliar o conhecimento existente sobre sinalização de qualidade ao estendê-lo ao setor de serviços, através da investigação de dois sinalizadores de qualidade: o preço e a responsividade. O controle comportamental percebido, entendido como a percepção do indivíduo sobre sua habilidade para realizar um comportamento, é proposto como moderador da relação entre as variáveis sinalizadoras e a qualidade percebida. Foram conduzidos dois estudos experimentais de desenho fatorial e intersujeitos para se testar as hipóteses formuladas com base na literatura. Os resultados de ambos os experimentos demonstram que a sinalização de qualidade através das variáveis preço e responsividade afetam a qualidade percebida. O segundo estudo suporta a hipótese envolvendo a moderação do controle comportamental percebido na relação entre a variável sinalizadora preço e a qualidade percebida, mas não entre responsividade e qualidade percebida. Esses resultados e as implicações encontradas são finalmente discutidos no capítulo de considerações finais.

Palavras-chave: sinalização de qualidade; preço; responsividade; controle comportamental percebido.

\begin{abstract}
Signaling theory states that signals are firms' actions that communicate information about the quality of a product. The main purpose of this research is to investigate the effect of signal quality in a service context, through the investigation of the signaling effects of price and responsiveness in a service context. Perceived behavior control, regarded as an individual's perception of the ability to perform a behavior, was proposed as a moderator between signaling variables and perceived quality. Two experimental studies with factorial and intersubject designs were conducted in order to test the hypotheses formulated from the literature review. Results from both experiments show that signaling quality through price and responsiveness can affect perceived quality. The second experiment supports the hypothesis of perceived behavior control moderation between price as a signaling variable and perceived quality, but not between responsiveness and perceived quality. These results and their implications are discussed in the final section of the paper.
\end{abstract}

Key words: signaling quality; price; responsiveness; perceived behavior control. 


\section{Introdução}

A economia da informação considera que diferentes partes em uma transação podem ter acesso a quantidades distintas de informação, ou seja, em uma interação de mercado entre compradores e vendedores pode existir assimetria da informação (Boulding \& Kirmani, 1993). Segundo a teoria da sinalização, a qualidade dos produtos não observáveis pelos clientes pode ser comunicada de diversas maneiras, incluindo o nome e a reputação de uma marca, propaganda, preço e garantias (Walker \& Johnson, 2009). Dessa forma, as empresas, através da sinalização de qualidade, podem emitir sinais, por meio das diversas variáveis de marketing, a fim de informar aos consumidores sobre a qualidade de seus produtos e, dessa maneira, evitar os problemas de mercado ocasionados pela assimetria de informações.

Percebe-se, assim, que a assimetria de informações parece estar mais presente no setor de serviços, pois este possui características específicas, como a intangibilidade e a inseparabilidade da produção e do consumo, que o fazem possuir mais atributos de experiência, isso é, atributos que podem ser avaliados apenas após a compra e o consumo do serviço (versus atributos de procura, característicos dos produtos físicos, que podem ser avaliados antes da compra) (Nelson, 1974; Parasuraman, Zeithaml, \& Berry, 1985). No entanto, embora haja um número razoável de estudos considerando elementos de marketing, como preço e propaganda, como sinalizadores de qualidade, até o presente momento, os estudos sobre sinalização têm sido direcionados para a área de produtos, existindo escassa literatura que indique como os mecanismos de sinalização podem ser utilizados no segmento de serviços ou adaptados às particularidades desse setor ${ }^{(1)}$.

Convém destacar que, embora extensiva pesquisa comportamental exista sobre como pistas (cues) advindas de elementos referentes ao ambiente de serviços - também chamados de evidências físicas - como decoração e mobília, afetam as percepções do consumidor, essa abordagem vê essas pistas como atalhos usados por consumidores cognitivamente preguiçosos. A teoria da sinalização considera um consumidor racional que espera que uma empresa honre o comprometimento implícito comunicado através de um sinal porque não honrar esse comprometimento é economicamente pouco inteligente. Assim, diferentemente da perspectiva comportamental, a abordagem de sinalização considera os incentivos da firma (Kirmani \& Rao, 2000).

Este trabalho pretende preencher essa lacuna, ampliando o conhecimento existente sobre a sinalização da qualidade para o setor de serviços, através da investigação de dois sinalizadores de qualidade: o preço e a capacidade de resposta às solicitações e às reclamações dos clientes (chamada nesse artigo de responsividade), em um contexto de prestação de serviços. A responsividade é considerada um aspecto fortemente relacionado à qualidade do serviço, e refere-se à capacidade de a empresa responder a solicitações e a problemas dos clientes (Zeithaml \& Bitner, 2003). Uma empresa pode sinalizar seu investimento em responsividade através de comunicação externa que ressalte essa capacidade aos clientes. Já Gerstner (1985) aponta que um preço alto pode refletir tanto uma elevada demanda por qualidade superior como altos custos de produção associados à qualidade superior. Assim, um serviço marcado com um alto preço implicaria um alto nível de qualidade e, portanto, valeria o preço acrescido.

Propõe-se, ainda, que o Controle Comportamental Percebido (CCP) atue como moderador da relação entre preço e responsividade com a qualidade percebida. O CCP foi definido como a facilidade ou a dificuldade percebida por um indivíduo em desempenhar um comportamento (Ajzen, 1991). Estendendo essa ideia ao contexto de compras, os indivíduos com baixo CCP estarão predispostos a realizar um esforço mais extensivo na hora de ponderar os atributos e as configurações de um serviço, e estariam mais suscetíveis aos sinais de qualidade emitidos pela empresa (como, por exemplo, a responsividade) do que os que possuem alto CCP.

Esse artigo consta de quatro partes. Na primeira, é trazida a fundamentação teórica, do modelo teórico e das hipóteses derivadas dele. Na segunda, são apresentados os dois estudos experimentais realizados, em termos de participantes e procedimentos, medidas e resultados. Em seguida, tem-se 
uma discussão geral dos resultados. Por fim, são discutidas as contribuições deste estudo, as suas limitações e os caminhos para futuras pesquisas.

\section{Sinalização de Qualidade}

A teoria da sinalização surgiu a partir dos estudos da área de economia da informação no contexto em que compradores e vendedores possuem informação assimétrica em uma interação de mercado (Boulding \& Kirmani, 1993). A assimetria da informação ocorre quando diferentes partes de uma transação podem ter acesso a quantidades distintas de informação, ou, em outras palavras, quando uma das partes possui uma informação privada, ou seja, sabe algo que a outra não sabe (Koetz, Santos, \& Kopschina, 2009). A falta de informação por parte do cliente sobre o serviço prestado pela empresa representa um problema na hora de selecionar um provedor de serviço (San Martín \& Camarero, 2005). Quando essa situação acontece, os clientes podem fazer inferência sobre os produtos e serviços oferecidos pelas empresas, de acordo com as informações ou evidências que cada uma destas opta por apresentar.

Sinais são, dessa forma, ações que o vendedor pode realizar para transmitir informação ao cliente sobre uma qualidade de um produto inobservável no momento de compra e agem como ações informativas e críveis para os clientes, porque as empresas que tentam utilizá-los de forma desonesta podem ter consequências econômicas desvantajosas (Rao, Qu, \& Ruekert, 1999). Imagine-se a situação onde uma empresa que oferece produtos de má qualidade decida oferecer garantias a seus clientes. Ela terá desvantagens econômicas devido ao alto índice de falhas de seus produtos e em decorrência das altas despesas que terá para cumprir com o acordo estabelecido. Contrariamente, as empresas que oferecem produtos de boa qualidade poderão afrontar os custos de oferecer garantias, porque tais despesas seriam menores. Os clientes esperam que as empresas honrem o compromisso implícito transmitido através dos sinais, porque, caso contrário, isto acarretaria situações de prejuízo monetário para as empresas (Kirmani \& Rao, 2000).

Pesquisadores na área de gestão tem aplicado a teoria da sinalização para explicar a influência da assimetria de informação em uma ampla gama de contextos de pesquisa (para uma revisão sobre a aplicação da teoria de sinalização na literatura de gestão, ver Connelly, Certo, Ireland, \& Reutzel, 2011). Particularmente, a sinalização tem sido um campo relevante para a área do marketing, pois diversos elementos do marketing podem ser utilizados para sinalizar a qualidade dos produtos e, assim, evitar os problemas de mercado ocasionados pela assimetria de informações (para uma classificação detalhada dos elementos do marketing utilizados para sinalizar qualidade, ver Kirmani \& Rao, 2000). Segundo Zeithaml (1988), a qualidade percebida é: (a) diferente da qualidade objetiva; (b) um nível maior de abstração do que a simples análise de um atributo do produto; (c) uma avaliação geral que, em alguns casos, parece-se com a atitude em relação a um produto; (d) um julgamento efetuado dentro de um conjunto de opções definidas pelo consumidor. Sendo assim, qualidade, em geral, e qualidade de serviço, em particular, são um construto difícil de explicar e medir (Monroe \& Krishnan, 1983). Segundo Grönroos (2003), a qualidade de um produto ou serviço, em particular, é qualquer coisa que o cliente perceba como tal. Bitner e Hubber (1994) apontam que qualidade em serviço é a impressão geral que o cliente tem sobre a inferioridade/superioridade relativas da empresa e seu serviços.

Parasuraman, Zeithaml e Berry (1988) encontraram que os consumidores consideram cinco dimensões em suas análises sobre qualidade dos serviços: confiabilidade, responsividade, segurança, empatia e tangíveis. Segundo esses autores, a qualidade dos serviços é mais difícil de ser avaliada pelos consumidores do que a qualidade dos produtos. A maior dificuldade na avaliação da qualidade dos serviços, em relação à dos produtos, diz respeito aos aspectos intangíveis do setor. Segundo Lutz (1986), quanto maior a proporção de atributos que podem ser avaliados antes da compra (atributos de procura) em relação aos atributos que podem ser identificados apenas ao longo do consumo do 
produto (atributos experimentais), maior a probabilidade de que a qualidade seja avaliada por meio de um julgamento cognitivo.

A sinalização traz, então, a cognição para a escolha de serviços com atributos experienciais. Assim, a dificuldade de avaliar a qualidade dos serviços pode ser minimizada por meio de estratégias como fornecimento de informações através de sinais aos consumidores, antes da compra do serviço.

\section{Preço como sinalizador de qualidade}

Leavitt (1954) foi um dos primeiros a testar empiricamente e encontrar que os compradores utilizam o preço como indicador da qualidade de um produto, chegando à conclusão de que o consumidor acredita que preços mais altos são indicadores de qualidade superior, ou seja, de que você ganha por aquilo que paga.

$\mathrm{O}$ efeito do preço-qualidade refere-se a quando o nível de preço sinaliza a qualidade do produto para o cliente (Kupiec \& Revell, 2001). A importância do preço como indicador de qualidade provavelmente será maior quando existirem poucos atributos que indiquem qualidade, ou quando o produto for difícil de avaliar, ou, ainda, quando as consequências da tomada de decisão forem consideráveis (Mitchel \& Greatorex, 1989). Desta forma, a área de serviços parece ser um cenário propício para o uso do preço como sinalizador de qualidade.

Do mesmo modo, vários autores têm encontrado variação no comportamento da correlação entre preço e qualidade dependendo de certos fatores, como categoria de produtos (Gerstner, 1985; Tellis \& Wernerfelt, 1987), fatores culturais (Erevelles, Roy, \& Yip, 2001), e o esquema preçoqualidade (Lichtenstein \& Burton, 1989; Rao \& Monroe, 1988), que será explorado ao final desta seção.

Estendendo a teoria da sinalização de qualidade através do preço dos produtos para a área dos serviços, encontra-se como uma exceção o trabalho de Toncar, Alon e Misati (2010), que testou o efeito esperado do preço na percepção de qualidade no setor de serviços. Eles apontaram que um serviço marcado com um alto preço pode ser percebido como contendo um alto nível de qualidade. $\mathrm{O}$ resultado do estudo demonstra que, quando os clientes são forçados a pagar um preço maior do que esperavam, eles reagem elevando suas expectativas em todas as facetas do encontro. Este raciocínio é consistente com o uso do preço como sinalizador de qualidade, pois, ao aumentar o preço, os clientes também esperam que aumente a qualidade do serviço.

Dadas as evidências empíricas sobre a relação existente entre preço e qualidade percebida, na qual alto preço sinaliza serviço de alta qualidade, propõe-se a primeira hipótese desse trabalho:

H1: A sinalização através do preço influencia positivamente a qualidade percebida do serviço por parte do cliente.

Conforme mencionado anteriormente, foram encontrados trabalhos que indicam a existência de fatores que podem moderar a relação existente entre preço e percepção de qualidade. Um fator encontrado como importante moderador dessa relação foi o nível de aceitação do indivíduo do esquema preço-qualidade (Lichtenstein \& Burton, 1989; Rao \& Monroe, 1988).

Lichtenstein e Burton (1989) explicam que um esquema causal é a concepção da maneira em que dois ou mais fatores interagem em relação a um efeito particular. No mercado atual, os clientes encontram uma grande quantidade de informação sobre os produtos, mas possuem uma habilidade limitada para processar estas informações (Lichtenstein \& Burton, 1989). Os indivíduos desenvolvem um repertório de ideias abstratas sobre a operacionalização e a interação dos fatores do mercado, conhecido como esquema (Kelley, 1973). Os esquemas ajudam os clientes a analisar de forma econômica e rápida as informações para lograr inferências causais razoáveis (Kelley, 1973). 
No contexto do comportamento do consumidor, investigadores encontraram que o esquema preço-qualidade é uma crença que guia o comportamento de compra de certos clientes, e que se mantém através de produtos e situações (Veeck \& Burns, 1995). Lichtenstein, Ridgway e Netemeyer (1993) explicam que alguns clientes são mais propensos a usar o preço como sinalizador da qualidade do que outros. Espera-se, portanto, que o nível de aceitação que os indivíduos têm do esquema preçoqualidade modere a relação de sinalização proposta nesta seção, em que o preço atua como sinalizador da qualidade.

H2: A sinalização através do preço influencia mais fortemente a qualidade percebida do serviço por parte do cliente quando esse acredita no esquema preço-qualidade.

\section{Responsividade como sinalizadora de qualidade}

$\mathrm{Na}$ literatura de marketing, a responsividade surgiu como uns dos critérios que os clientes utilizam para avaliar a qualidade dos serviços. Parasuraman, Zeithaml e Berry (1985) realizaram uma pesquisa exploratória com o objetivo de definir, delimitar e medir o construto de qualidade. Esse estudo revelou que os critérios utilizados pelos clientes para avaliar qualidade dos serviços são basicamente os mesmos: acessibilidade, comunicação, capacidade, cortesia, credibilidade, confiabilidade, seguridade, entendimento, tangíveis e responsividade. Em estudo posterior, os mesmos autores (1988) restringem a qualidade de serviços, medida chamada de SERVQUAL, a cinco fatores principais: confiabilidade, empatia, segurança, tangíveis e responsividade. Essa última é definida como a vontade de ajudar os clientes e fornecer um serviço sem demora (Parasuraman et al., 1985), estando, assim, vinculada à percepção de atenção e prontidão no trato com as solicitações, questões, reclamações e problemas dos clientes (Zeithaml \& Bitner, 2003). Johnston (1995) definiu responsividade como a velocidade e a pontualidade de entrega do serviço. Isso inclui a capacidade de prestadores de serviços para responder prontamente às solicitações dos clientes com o mínimo tempo de espera.

Vários autores destacam a importância da responsividade como fator determinante da qualidade (Johnston, 1995; Malhotra, Ulgado, Agarwal, \& Baalbaki, 1994; Parasuraman et al., 1985). Parasuraman et al. (1985) afirmam que a responsividade é um determinante chave da qualidade. Similarmente, Johnston (1995) indica que a responsividade é um determinante crucial da qualidade, sendo o principal componente em proporcionar satisfação em serviços, enquanto que sua falta é a principal fonte de insatisfação. Assim, neste trabalho, investiga-se a responsividade como variável sinalizadora de qualidade, sendo este, até onde se sabe, o primeiro estudo acadêmico em que se avalia este aspecto do serviço, no contexto de sinalização.

A lógica para se abordar responsividade como uma sinalizadora de qualidade é a seguinte: as empresas podem destacar sua capacidade de resposta aos clientes através de comunicação externa, ressaltando a predisposição e a disponibilidade da empresa em responder às solicitudes dos clientes, proporcionando estrutura adequada que facilite o contato do cliente com a empresa, e oferecendo mecanismo de reclamações (por exemplo, SAC 24 horas), com o objetivo de melhorar o serviço de recuperação de falhas. Esse tipo de comunicação explicitamente comunica a abertura da empresa às solicitações e às reclamações dos clientes. Além disso, poderia indicar também que os problemas serão solucionados da forma mais adequada e no menor tempo possível e, dessa maneira, elevar a percepção de qualidade que o cliente tem do serviço. Parasuraman et al. (1985) afirmaram que clientes que são advertidos de que a empresa está tomando medidas concretas para servir seus interesses são suscetíveis de perceber o serviço de forma mais favorável. Relacionando a teoria da sinalização com essa ideia, pode-se inferir que empresas que explicitamente sinalizem alta responsividade podem ser percebidas como oferecendo um serviço de alta qualidade.

Seguindo esse raciocínio, se uma empresa com baixo nível de qualidade decide utilizar esse sinal sem possuí-lo, terá desvantagem econômica por dois motivos. Primeiramente, por não contar com os meios necessários para resolver as solicitudes dos clientes. Os clientes esperam que as informações transmitidas sejam cumpridas, caso contrário, deixam de comprar o serviço e, dessa 
forma, prejudicam a receita da empresa. Contrariamente, as empresas que possuem essa capacidade e utilizam esse sinal serão beneficiadas, pois elas poderão cumprir com o acordo sinalizado e, dessa forma, não comprometerão vendas futuras. O segundo motivo refere-se ao fato de que a empresa terá consequências desfavoráveis devido ao alto número de falhas no serviço oferecido, as quais poderão surgir caso a empresa ofereça serviços com baixa qualidade e, assim, sobrecarregue demasiadamente essa estrutura. Desse modo, necessitará fazer maiores investimentos para solucionar os problemas dos clientes; enquanto que uma empresa que possua esse sinal e ofereça serviços de alta qualidade poderá afrontar esses custos (referentes a eventuais falhas) sem maiores problemas.

É importante ressaltar que, entre os demais fatores que compõem a SERVQUAL (empatia, segurança, confiabilidade e tangíveis), apenas os tangíveis, afora a responsividade, parecem se enquadrar como sinalizadores de qualidade inequívocos, tendo em vista que sinais são ações desenvolvidas para emitir um parecer sobre a qualidade de um produto que não é perceptível, no momento da negociação, ao comprador (Rao et al., 1999). Para uma ação potencialmente estabelecer um sinal, ela deve ter um custo para a empresa. Além disso, é fundamental que a outra parte tenha conhecimento de que esse custo, no caso de não cumprimento do que está implícito na sinalização, será maior para a empresa do que se ela de fato oferecer o padrão de qualidade que está sendo sinalizado (Koetz et al., 2009). Tendo isso em mente, parece improvável que a empresa possa utilizar a confiabilidade e a empatia dos funcionários, por exemplo, como sinalizadores, uma vez que o investimento (custo associado) nesses quesitos não parece ser tão explícito e, como no caso da reserva de um serviço como o de hotelaria, o contato com os funcionários e mesmo com o ambiente onde será prestado o serviço (i.e., tangíveis) só ocorre após a compra do mesmo. Com base no exposto, propõese, na hipótese 3 desse trabalho, a utilização do atributo responsividade como sinalizador da qualidade de serviços.

H3: A sinalização através da comunicação de responsividade influencia positivamente a qualidade percebida do serviço por parte do cliente.

Além disso, supõe-se que a interação entre preço e responsividade poderá afetar as percepções dos consumidores sobre a qualidade dos serviços. Assim, quando o preço for acima da média e a responsividade for alta, é provável que a qualidade percebida pelos clientes seja mais alta do que quando apenas um desses elementos (preço ou responsividade) estiver acima da média. No entanto, como não há literatura sobre o impacto da interação entre esses dois fatores, ela será tratada como uma questão empírica nesse trabalho, isso é, como uma investigação exploratória, sem hipótese formal.

\section{Controle Comportamental Percebido}

Controle comportamental percebido (CCP) refere-se à percepção própria de um indivíduo da capacidade de desempenhar um comportamento particular (Ajzen, 1991). Segundo a teoria do comportamento planejado de Ajzen (1991), as pessoas formam uma intenção de realizar um comportamento de acordo com três aspectos cognitivos: (a) atitude (avaliação cognitiva global da realização do comportamento); (b) norma subjetiva (pressão social percebida para executar um comportamento); e (c) CCP (facilidade ou dificuldade percebida por um indivíduo em desempenhar um comportamento).

Apesar dos esforços de Ajzen (1991) em explicar a função dos determinantes cognitivos na formação da intenção comportamental, outro extremo da investigação tem encontrado que a intenção também pode ser constituída baseada em critérios heurísticos que requerem processos menos deliberativos (Chaiken, 1980; Ouellette \& Wood, 1998). As pessoas podem usar seu comportamento passado como base heurística para suas decisões posteriores (Taylor, 1975). Por exemplo, eles podem simplesmente assumir que as condições que os levaram ao seu comportamento anterior também existem na situação presente e podem repetir o comportamento sem se preocupar em verificar essa suposição (Albarracin \& Wyer, 2000). 
De acordo com essas informações, a intenção comportamental das pessoas nem sempre se encontra configurada de acordo com deliberações cognitivas. Kidwell e Jewell (2010) investigam como a motivação pode afetar a utilização dos processos cognitivos e heurísticos na formação da intenção comportamental. Segundo os autores, quando uma intenção comportamental se forma, frequentemente é resultado de processos motivacionais que direcionam o comportamento em direção a algum objetivo. Park e Mittal (1985) sugerem que a motivação para realizar um comportamento pode estar baseada na confiança do indivíduo em realizar dito comportamento satisfatoriamente. Desta forma, Kidwell e Jewell (2010) encontram que a motivação e o CCP podem afetar a intenção comportamental da seguinte maneira: as pessoas que percebem um alto nível de controle sobre um comportamento normalmente são confiantes em sua capacidade de executar tal comportamento. Como resultado, esses indivíduos podem experimentar complacência e, portanto, falta de motivação para se envolver em esforço cognitivo para aprimorar seus recursos existentes na formação de uma intenção comportamental; em contraste, os indivíduos que possuem baixa percepção de controle são menos confiantes em suas habilidades para desempenhar um comportamento, e, geralmente, estão insatisfeitos com seu nível de habilidade atual. Essa diferença entre a habilidade atual e a desejada os motiva para se comprometerem em um esforço cognitivo, e também a reformularem certas atitudes na hora de tomar uma decisão.

Estendendo essa ideia a um contexto de avaliação de qualidade de serviço, espera-se que o nível de CCP afete a motivação dos indivíduos em realizar um esforço cognitivo. Dessa maneira, os indivíduos com alta CCP possivelmente basearão suas intenções no processo heurístico de experiências passadas, ao invés de se envolverem em um processo mais deliberado dos atributos que exija um alto esforço cognitivo. Enquanto que os indivíduos com baixa CCP estarão mais propensos a realizar um esforço maior e, dessa maneira, estarão mais susceptíveis de ponderar os sinais emitidos pela empresa para sinalizar a qualidade do serviço (no caso desse trabalho, sinais de preço e responsividade).

Com base na discussão anterior, propõe-se que o CCP modere a relação entre as variáveis sinalizadoras (preço e responsividade) e a qualidade percebida, de tal forma que, entre pessoas com alto $\mathrm{CCP}$, essa relação seja menor do que entre pessoas com baixo CCP. A base teórica até aqui abordada serve como base para as seguintes hipóteses:

H4: A relação entre a variável sinalizadora preço e a qualidade percebida será menor (maior) em indivíduos com alto (baixo) CCP.

H5: A relação entre a variável sinalizadora responsividade e a qualidade percebida será menor (maior) em indivíduos com alto (baixo) CCP.

A Figura 1 traz o modelo teórico do trabalho e resume as hipóteses formuladas nesta pesquisa.

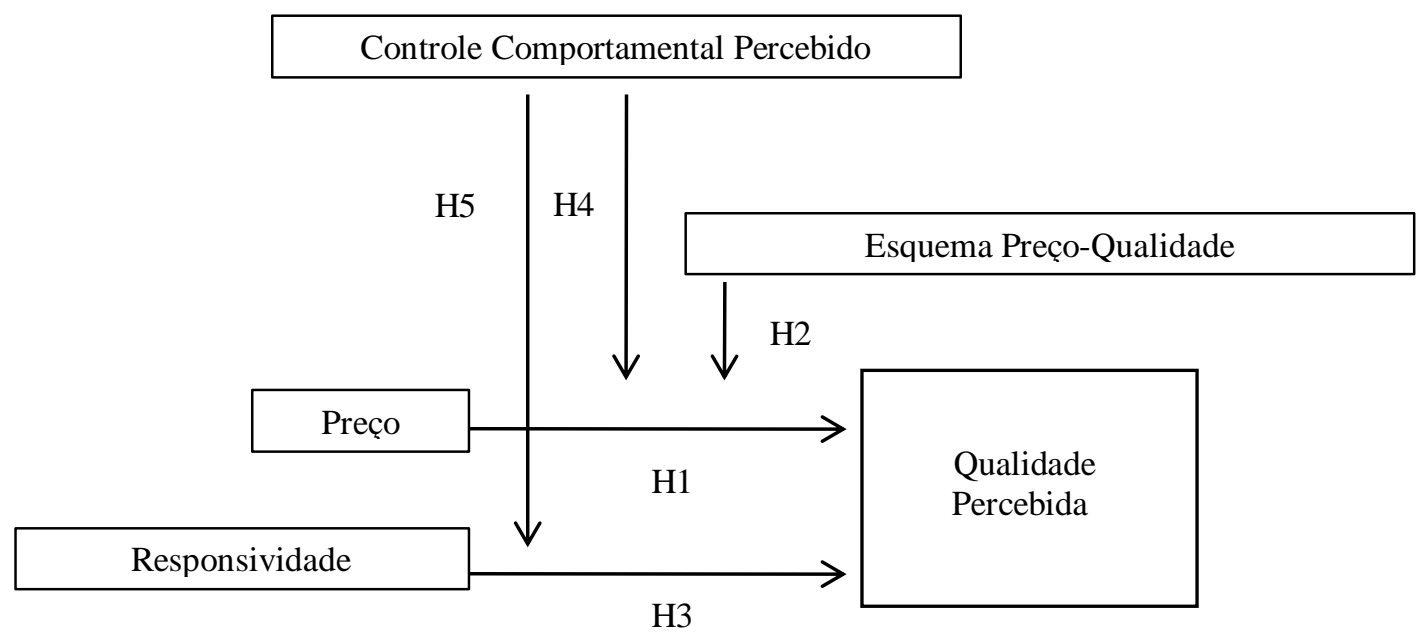

Figura 1. Modelo Teórico do Trabalho. 


\section{Estudo 1}

O primeiro estudo tem como objetivo analisar a influência do preço e da responsividade na percepção de qualidade de um serviço (H1 e H3). Utilizou-se um desenho experimental intersujeito 3 x 2, com três situações de preço (preço superior à média dos competidores, preço igual à média dos competidores e preço abaixo da média dos competidores), e duas situações de responsividade da empresa (baixa e alta responsividade, manipuladas através de indicação de horário de atendimento da recepção - das 8 às 20h, no caso de baixa responsividade; ou 24 horas, no caso de alta responsividade; e SAC, ausente na baixa e presente na alta responsividade). Note-se que se optou por essa forma de se manipular a responsividade da empresa por ser essa última vinculada à atenção e à prontidão no trato com as solicitações, questões, reclamações e problemas dos clientes (Zeithaml \& Bitner, 2003). Desta forma, acredita-se que um horário estendido de atendimento da recepção (e.g. 24 horas) e a presença de um SAC sinalize, de forma eficiente, a disposição da empresa para responder às solicitações e às reclamações dos clientes. Porém, como não foram encontrados outros estudos que tenham manipulado de forma experimental essa variável, pré-testes foram feitos para verificar-se a adequação dessa manipulação.

Depois da apresentação dos cenários, mediu-se a percepção de qualidade que os participantes têm do serviço que será oferecido pelo hotel.

Inicialmente, foi realizado um pré-teste qualitativo com 12 alunos, no qual foram verificados a clareza e o entendimento dos cenários, e também de todos os itens das escalas a serem aplicados no experimento. Os estudantes foram abordados individualmente nos corredores e espaços livres das escolas, fora do horário de aula, e foram convidados a participar da pesquisa. Foi entregue a cada um deles o questionário e o pedido que lessem com atenção as informações contidas para responder às perguntas, e também que se manifestassem em caso de dúvidas ou dificuldades. Ao final do instrumento, foi feita uma questão para se detectar se os respondentes conseguiam descobrir o objetivo do estudo e, dessa forma, apresentar algum viés ao respondê-lo (demand effect). Nenhum respondente pode identificar adequadamente o objetivo do experimento. De forma particular, os respondentes foram questionados, ao final, a que qualidades da empresa o horário de atendimento da recepção do hotel e a presença (ou não) de um SAC estariam se referindo. Praticamente todos os estudantes associaram esses fatores à atenção e à disposição da empresa a ajudar seus hóspedes no que for preciso e a resolver falhas ocorridas no hotel, quando necessário (isso é, características que são a base do conceito de responsividade). Ainda, nenhum participante desse pré-teste percebeu as fotos dos hotéis escolhidas como diferentes entre si, isso é, caracterizando um hotel de maior ou menor qualidade.

Após esse primeiro pré-teste, um segundo, dessa vez quantitativo, com 21 alunos de graduação de uma grande universidade pública brasileira (mesma população do estudo principal) foi realizado com o objetivo de verificar a eficácia das manipulações feitas, a consistência interna da escala de qualidade percebida utilizada e a adequação do setor de serviço escolhido. A partir dessa fase, pequenas alterações foram realizadas no instrumento de coleta, entre elas: os nomes dos hotéis utilizados foram modificados por motivos de semelhança com hotéis da região, o que poderia causar algum viés.

Finalmente, testou-se a adequação do setor hoteleiro como possível contexto de pesquisa, pelo fato de se poder fazer uma reserva on-line, o que permite a manipulação da responsividade, e também por ser possível ter-se preços bastante diferenciados para produtos na mesma categoria de serviços (hotéis 3 estrelas, por exemplo), o que nos ajuda a controlar outros elementos, como o próprio elenco de serviços agregados que poderiam ser oferecidos pelo hotel. O setor hoteleiro foi considerado adequado para essa pesquisa, uma vez que $68,1 \%$ dos estudantes afirmaram ter familiaridade com hospedagem em hotéis superior à média da escala. Posteriormente, foi executado o estudo principal, cujos detalhes são descritos a seguir. 


\section{Participantes e procedimento}

O primeiro estudo foi aplicado a uma amostra de 133 estudantes de graduação (56,8\% homens, média de idade de 23,7 anos) de uma grande universidade pública brasileira. Os alunos foram abordados nas turmas e convidados a participar voluntariamente da pesquisa. No início do questionário, um breve texto explicava que o objetivo da pesquisa era conhecer a opinião dos respondentes em relação às práticas utilizadas no setor hoteleiro. A seguir, eram distribuídos os cenários de maneira aleatória entre os participantes.

O seguinte texto foi apresentado a todos os participantes: Você quer reservar um quarto de hotel para uma viagem ao exterior. Em uma página de reservas você encontra as seguintes opções. A seguir, foi apresentada uma página simulando um site de internet contendo três opções de hotéis. Essa página continha fotografia do hotel visto do exterior, uma breve descrição, os serviços oferecidos, incluído informações sobre responsividade e preço ${ }^{(2)}$ de cada uma das opções. Dessa forma, o pesquisado podia comparar e perceber a diferença de preço e serviços oferecidos (informações sobre responsividade) entre as distintas opções. Na continuação, o texto indica qual é a opção escolhida pelo respondente. $\mathrm{O}$ hotel escolhido era sempre o mesmo (Hamptom Hotel), assim como a descrição do hotel (não há maneira mais espetacular de apreciar uma cidade do que do Hampton Hotel. Este hotel está convenientemente situado perto), a única coisa que mudava era o preço e o nível de responsividade com relação às outras duas opções. Ressalta-se ainda que, como forma de unificar ainda mais as ofertas, todas as 3 opções eram apresentadas como tendo 3 estrelas (classificação bastante utilizada no setor hoteleiro) e as fotos escolhidas para os três hotéis são bastante similares (fachadas de prédios grandes), assim como os nomes (Lexington and Wellington, dos outros dois hotéis). Note que o uso de um website para apresentação dos cenários foi por ser essa uma forma muito utilizada de se buscar hotéis, especialmente entre a população de estudantes. No entanto, não se buscou avaliar características do website como sinalizadoras de qualidade.

Logo após a apresentação do cenário, eram realizadas as perguntas para a checagem das manipulações, e, a seguir, as questões sobre percepção de qualidade. Para concluir, eram feitas perguntas sobre: realidade do cenário, familiaridade com o contexto, ocorrência de um incidente similar, e tempo em que foi feita a última reserva desse serviço. Também foram coletados dados demográficos, como gênero, idade e renda familiar do pesquisado. Por último, também foi perguntado sobre o provável objetivo da pesquisa, com a intenção de identificar efeitos de demanda, que podem interagir com os efeitos das variáveis independentes levando a falsos resultados positivos ou negativos em experimentos (Sawyer, 1975). Não foi encontrado nenhum desses casos entre os respondentes. Após testes de outliers (através do teste de resíduos $\mathbf{Z}$ Score), dos 133 respondentes, restaram 116 para a análise final. Em média, os grupos (referentes a cada cenário) foram compostos por 19 (dezenove) participantes, próximo, assim, ao número de 20 (vinte) respondentes por cenário sugerido por Hair, Babin, Money e Samouel (2005).

\section{Medidas}

Para conferir a eficácia das variáveis manipuladas, foram realizadas perguntas de verificação aos participantes após a apresentação dos cenários. Assim, no instrumento de coleta, foi inserida uma questão - O preço oferecido pela empresa é: - com o objetivo de avaliar a percepção dos respondentes sobre as diferenças entre os preços dos hotéis oferecidos, a qual foi avaliada por meio de uma escala de 7 pontos, cujas extremidades são muito abaixo do preço da concorrência e muito acima do preço da concorrência. Do mesmo modo, uma questão para avaliar a manipulação da percepção de responsividade foi feita. A questão foi: A capacidade de atendimento da empresa às solicitações/reclamações dos clientes é, a qual também foi avaliada por meio de uma escala de 7 pontos, cujas extremidades são baixa capacidade de resposta às solicitações - reclamações dos clientes e alta capacidade de resposta às solicitações - reclamações dos clientes.

A seguir, três itens, adaptados de Boulding e Kirmani (1993) e Kirmani e Wright (1989), avaliaram a qualidade percebida do serviço por meio de escalas de 7 pontos, considerando o conforto 
oferecido pelo hotel escolhido comparado com os outros hotéis (muito abaixo da média $=1$; muito superior da média $=7$ ), o atendimento prestado pelos funcionários do hotel escolhido comparado com os outros hotéis (muito abaixo da média $=1$; muito superior da média $=7$ ) e a qualidade geral do hotel escolhido comparado com os outros hotéis (muito baixa $=1$; muito alta $=7$ ). A variável qualidade percebida utilizada nos testes a seguir foi criada a partir da média dessas três questões $(\alpha=0,78)$.

Além disso, duas variáveis foram inseridas para avaliar a realidade do cenário. As questões foram as seguintes: A situação apresentada pode ocorrer na vida real?; Eu consigo me imaginar em uma situação similar a essa?, avaliadas através de uma escala Likert $(1=$ discordo totalmente e $7=$ concordo totalmente). A percepção de realismo dos cenários foi alta (ambas significativamente acima do ponto médio da escala, de 4, p<01), com médias nessas duas questões de 6,20 e 5,81, respectivamente.

Foram, ainda, incluídas as seguintes variáveis de controle: familiaridade e há quanto tempo o sujeito havia feito a última reserva em hotel. O nível de familiaridade com hospedagem em hotéis foi avaliado por meio de uma escala Likert de 7 pontos, cujas extremidade foram pouca familiaridade e muita familiaridade. O tempo de reserva foi medido em uma variável nominal (esse ano, pelo menos uma vez nos últimos três anos, há mais de três anos, nunca).

Ressalta-se que, tanto as variáveis demográficas (sexo e idade) quanto as de controle foram testadas como covariável no modelo, e nenhuma delas apresentou impacto na percepção da qualidade $(\mathrm{p}>0,05)$.

\section{Resultados}

\section{Checagem das manipulações}

Os resultados demonstraram que as diferenças entre as médias da variável preço $(\mathrm{F}(2,78)=$ $149,23 ; \mathrm{p}<0,01)$, nas três condições manipuladas $(\mathrm{M}=2,46, \mathrm{M}=4,14$, e $\mathrm{M}=5,70$ para abaixo da média, na média e acima da média de preço, respectivamente) e entre as médias da variável responsividade, nas duas condições manipuladas $(\mathrm{M}=2,22$ e $\mathrm{M}=5,79$ para baixa e alta responsividade, respectivamente), foram significativas $(F(1,185)=226,88 ; p<0,01)$, indicando que os respondentes perceberam as diferenças nos níveis de preços e responsividade nas condições manipuladas.

\section{Qualidade percebida}

A análise prosseguiu para a verificação do efeito das variáveis preço e responsividade na qualidade percebida. A análise de variância (ANOVA) revelou efeito significativo do preço na percepção de qualidade do serviço $(\mathrm{F}(2,60)=8,11 ; \mathrm{p}<0,01)$, e da responsividade percebida através do atendimento 24 horas e SAC $(F(1,60)=75,35 ; \mathrm{p}<0,01)$, suportando, dessa forma, as hipóteses 1 e 3 deste estudo. Mais especificamente, a percepção de qualidade foi maior em cenários com alta responsividade $(M=4,86)$ que em cenários com baixa responsividade $(M=3,67)$. Em relação ao efeito principal do preço, a percepção de qualidade de acordo com três níveis apresentou as seguintes médias: preço acima da média $(\mathrm{M}=4,65)$; preço na média $(\mathrm{M}=4,05)$ e preço abaixo da média da concorrência $(M=4,07)$. Os resultados do teste Post-hoc LSD indicaram que a percepção de qualidade no caso do alto preço foi significativamente diferente em relação ao preço na média $(\mathrm{p}<0,01)$ e ao o preço abaixo da média $(\mathrm{p}<0,01)$. No entanto, não foi encontrada diferença significativa entre estes dois últimos níveis $(\mathrm{p}=0,94)$. Além disso, foi encontrado efeito de interação significativo das variáveis preço e responsividade na percepção de qualidade $(\mathrm{F}(2,60)=4,65 ; \mathrm{p}<0,05)$. A Figura 2 ilustra essa interação. 


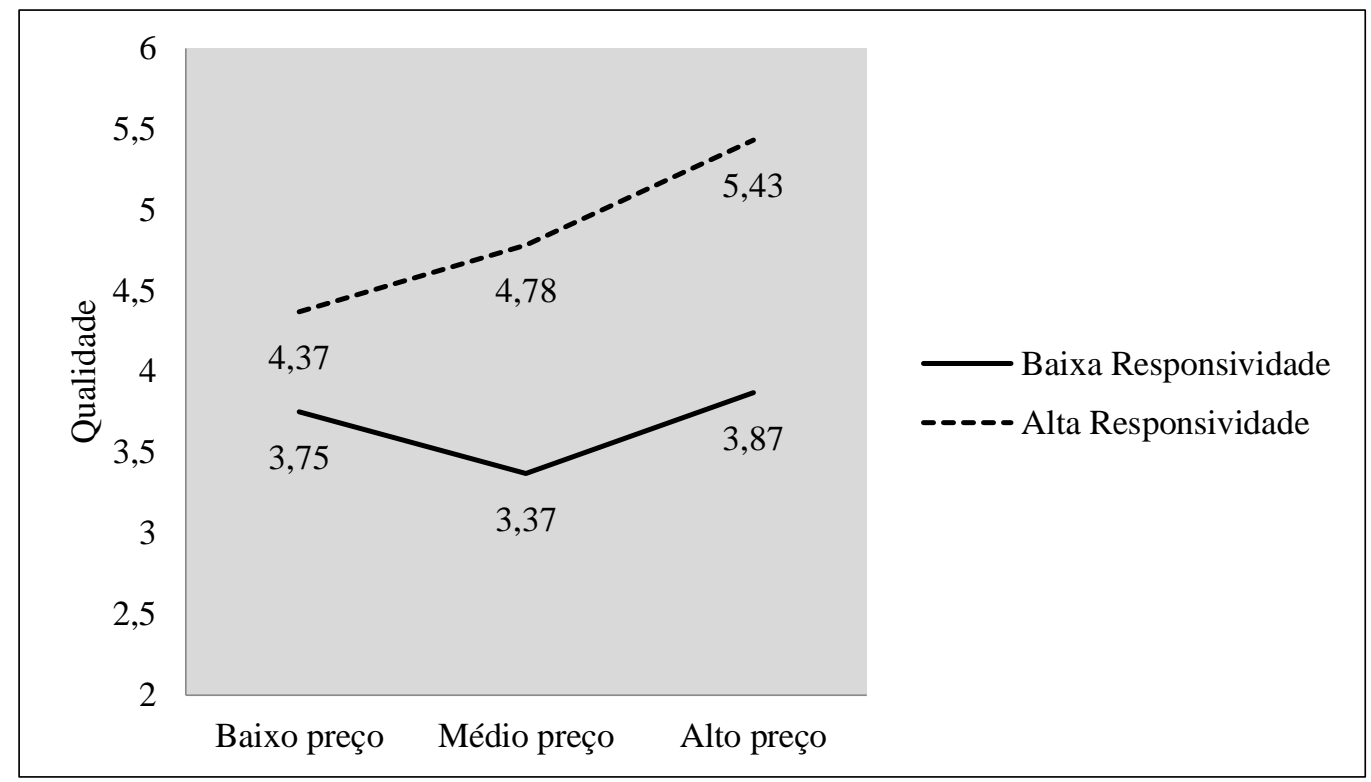

Figura 2. Efeito Interativo entre Preço e Responsividade na Qualidade Percebida.

Para se entender mais profundamente essas interações entre preço e responsividade, foram realizados testes Post-hoc (LSD). Para se realizar esses testes, é necessário se criar sub-grupos. Inicialmente, separou-se apenas o grupo de baixa responsividade, para investigar-se o efeito do preço nessa situação. O resultado do teste LSD indicou que, entre sujeitos expostos à baixa responsividade, as médias da qualidade percebida para os diferentes níveis de preço não são diferentes $(M=3,75, M=$ 3,37, e $\mathrm{M}=3,87$ para abaixo da média, na média e acima da média de preço, respectivamente, $\mathrm{p}>0,05$,). Da mesma forma, separaram-se apenas os sujeitos expostos à alta responsividade, entre eles, as médias de qualidade para os diferentes níveis de preço são diferentes $(M=4,37, M=4,78$, e $M=$ 5,43 para abaixo da média, na média e acima da média de preço, respectivamente). Entre estes, a qualidade foi percebida como significativamente superior no nível mais alto do preço (diferente dos níveis baixo e médio, $\mathrm{p}<0,05)$. Já o preço abaixo da concorrência não indicou menor qualidade, comparando-se com o preço na média $(\mathrm{p}>0,05)$.

\section{Discussão}

Os resultados do estudo 1 confirmam a influência da percepção de responsividade por parte da empresa na percepção de qualidade no serviço. A percepção de qualidade é superior quando a responsividade é percebida como alta, porém a percepção de qualidade diminui quando a percepção de responsividade é baixa. Dessa forma, foi suportada a H3. Em relação ao preço também foi encontrado o impacto significativo deste na percepção de qualidade, confirmando a H1. Assim, quanto maior o preço, maior foi a percepção de qualidade do hotel.

Foi encontrada interação significativa entre preço e responsividade, de forma que, quando a responsividade é baixa, não há diferença nas médias de qualidade, mesmo com preços distintos; já quando a responsividade é alta, há diferenças entre as médias de qualidade entre sujeitos expostos a cenários de alto preço comparados com os expostos a cenários com preço na média e abaixo da média, mas não entre esses dois últimos. Este resultado indicando que o preço abaixo da concorrência não sinalizou menor qualidade, comparando-se com o preço na média, pode ser uma consequência da familiaridade dos respondentes em relação ao contexto, os quais podem ter conhecimento de que o preço abaixo da média nem sempre implica qualidade inferior do serviço, principalmente quando se trata de sites de busca, em que frequentemente é possível encontrar preços promocionais de hotéis bem conceituados que oferecem preços bem mais acessíveis. Outra explicação para este resultado poderia ser a utilização de estrelas sinalizadoras de categorias de hotéis, as quais indicam a que categoria pertence o mesmo. Dessa forma, os respondentes poderiam perceber semelhanças de qualidade entre hotéis que estão em uma mesma categoria. 
Já com relação ao preço ser significativo apenas em situações de alta responsividade, esse resultado pode ser oriundo do fato de que a responsividade é considerada uma dimensão determinante da qualidade dos serviços (Johnston, 1995; Parasuraman et al., 1985). Por isso, essa variável demonstrou ter efeito preponderante na percepção de qualidade (comparando-se ao preço). Portanto, quando a responsividade é baixa, sua influência na percepção de qualidade dificilmente poderá ser substituída ou compensada por outra variável sinalizadora (nesse caso, um preço mais alto).

Outra explicação pode estar relacionada aos sinais intrínsecos e extrínsecos da qualidade, apontados por Olson (1977). Segundo o autor, os sinais intrínsecos não podem ser mudados sem alterar a composição do produto (nesse caso, a responsividade). Enquanto que os extrínsecos estão relacionados ao produto, mas não formam parte deste (neste caso, o preço). De acordo com essa informação, o preço pode ser modificado arbitrariamente pela empresa, sem que isso afete a qualidade do serviço oferecido. Contrariamente, no caso da responsividade, por ser um sinal intrínseco, sua alteração ocasionaria modificações na composição do serviço e também requereria maiores esforços e recursos. Assim, a responsividade afetaria, de forma mais direta, o serviço oferecido, e também seria um sinal mais confiável da qualidade do serviço.

\section{Estudo 2}

O segundo experimento foi intersujeitos e teve um desenho de $3 \times 2 \times 2$, com três contextos em relação ao preço (preço superior à média dos competidores, preço igual à média dos competidores, e preço abaixo da média dos competidores), duas situações em relação à responsividade (baixa e alta responsividade), e duas concernentes ao controle comportamental percebido (CCP) (baixo CCP e alto CCP). Sendo assim, 12 cenários foram desenhados. Foram testados novamente os efeitos das variáveis preço $(\mathrm{H} 1)$ e responsividade $(\mathrm{H} 3)$ sobre a qualidade percebida, investigando a existência de moderação do CCP nas relações entre os sinalizadores e a qualidade (H4 e H5). Também foi testado o efeito de moderação do esquema preço-qualidade na relação entre preço e qualidade (H2). Similar ao primeiro estudo, o contexto escolhido para desenvolver este experimento foi o setor hoteleiro.

Para realizar a manipulação do CCP, foi necessária a aplicação de um questionário que simulava medir a habilidade dos participantes em relação às compras on-line. Seguindo o procedimento de Kidwell e Jewell (2010), o resultado fictício deste teste (indicando baixo ou alto CCP) foi entregue aos participantes antes da apresentação dos cenários. Com base na literatura sobre CCP, esperava-se encontrar a influência dessa variável na relação entre os sinalizadores e a qualidade percebida (H4 e H5).

Posterior à entrega dos resultados do primeiro teste, todos os respondentes recebiam um dos 12 cenários. Similar ao primeiro estudo, mediu-se a percepção de qualidade que os participantes têm do serviço a ser prestado pelo hotel.

\section{Participantes e procedimento}

Da mesma forma que no primeiro estudo, antes da aplicação deste experimento foi realizado um pré-teste qualitativo com 7 alunos de graduação. Não foram identificados problemas em relação aos cenários ou medidas utilizadas, provavelmente porque as escalas eram praticamente as mesmas utilizadas no estudo 1. Portanto, passou-se à aplicação do estudo principal.

O segundo estudo foi aplicado a 257 alunos de graduação (60,9\% homens, média de idade de 22,8 ) de uma grande universidade pública brasileira. Para a realização desse estudo, foi necessário realizar a coleta em duas fases (dois dias não necessariamente consecutivos). Na primeira fase, foi aplicado o teste fictício sobre compras on-line e solicitado aos alunos que colocassem seus últimos três números de matrícula no questionário. Isso com o objetivo de receber, no segundo dia, o resultado desse primeiro teste. 
No segundo dia, eram entregues aos participantes os resultados do teste previamente aplicado, de acordo com os números de matrícula. O objetivo da distribuição dos resultados era manipular o CCP dos indivíduos. Para conseguir tal objetivo, os resultados entregues aleatoriamente eram de dois tipos: (positivo) sua habilidade e conhecimentos são muito superiores aos dos demais participantes desse teste; (negativos) sua habilidade e conhecimentos são muito inferiores aos dos demais participantes desse teste. A seguir, os cenários que manipulavam responsividade e preço foram distribuídos de maneira aleatória entre os participantes.

A diferença principal entre o primeiro estudo e o segundo foi a manipulação prévia do CCP, manipulada em dois níveis (alto e baixo). Após a coleta dos dados e seguindo o procedimento de Kidwell e Jewell (2010), foi informado aos participantes que os resultados providos sobre compras online eram fictícios e foram distribuídos de forma aleatória.

Dos 257 respondentes, após a retirada de outliers através do teste de resíduos $\mathbf{Z}$ Score, restaram 220 para a análise final. Em média, os grupos (referentes aos 12 cenários) foram compostos por 18 participantes.

\section{Medidas}

As medidas utilizadas nesse estudo foram praticamente as mesmas do estudo 1 (qualidade percebida, $\alpha=0,84$ ), à exceção da variável para se testar a manipulação de controle comportamental percebido e do esquema preço-qualidade. No questionário utilizado, foi introduzida uma questão para avaliar a manipulação sobre o CCP. A questão foi: Qual você diria que é seu grau de habilidade e conhecimento sobre compras on-line?, que foi avaliada por meio de uma escala Likert de 7 pontos cujas extremidades são muito baixo e muito alto.

Também, ao final do questionário, foi inserida a escala de Esquema preço-qualidade adaptada de Lichtenstein e Burton (1989), composta de 4 itens avaliados em uma escala de 7 pontos, cujas extremidades são $1=$ discordo totalmente e $7=$ concordo totalmente. A escala foi composta pelas seguintes questões: Em geral, quanto maior é o preço de um produto/serviço, maior é a qualidade; a frase, você recebe o que paga é geralmente verdade; O preço de um produto/serviço é um bom indicador da sua qualidade; e Você sempre tem que pagar um pouco mais pelo melhor. A variável esquema utilizada na análise de moderação, foi criada a partir da média dessas quatro questões $(\alpha=0,79)$.

Foram, ainda, incluídas mesmas variáveis de controle do Estudo 1: familiaridade e há quanto tempo o sujeito havia feito a última reserva em hotel. Tanto essas variáveis quanto as variáveis demográficas foram testadas como covariáveis no modelo, nenhuma apresentando impacto na percepção da qualidade ( $\mathrm{p}>0,05)$.

\section{Resultados}

\section{Checagem das manipulações}

Primeiramente, foi conduzida a checagem da manipulação das variáveis preço e responsividade. Os resultados demonstraram que as diferenças entre as médias da variável preço nas três condições manipuladas $(\mathrm{F}(2,148)=338,42 ; \mathrm{p}<0,01 ; \mathrm{M}=2,09, \mathrm{M}=4,11$, e $\mathrm{M}=5,64$, para abaixo da média, na média e acima da média de preço, respectivamente) e entre as médias da variável responsividade nas duas condições manipuladas $(\mathrm{F}(1,324)=451,09 ; \mathrm{p}<0,01 ; \mathrm{M}=2,38$ e $\mathrm{M}=5,87$, para baixa e alta responsividade, respectivamente) foram significativos, indicando que os respondentes perceberam as diferenças nos níveis de preços e responsividade nas condições manipuladas. Também foi realizada a checagem da manipulação da variável CCP. Os resultados da One-Way ANOVA demonstraram que a diferença entre as médias da variável CCP nas duas condições manipuladas $(\mathrm{M}=$ 3,85 e $\mathrm{M}=5,44$, para baixo e alto $\mathrm{CCP}$, respectivamente) foi significativa $(\mathrm{F}(1,459)=66,52 ; \mathrm{p}<0,01)$. 


\section{Qualidade percebida}

A análise prosseguiu para a verificação do efeito das variáveis preço, responsividade e CCP na qualidade percebida. A análise de variância (ANOVA) revelou efeito direto significativo do preço na percepção de qualidade do serviço $(\mathrm{F}(2,139)=3,92 ; \mathrm{p}<0,05)$, e da responsividade, percebida através do atendimento 24 horas e SAC $(F(1,139)=131,99 ; \mathrm{p}<0,01)$. Dessa forma, confirmando novamente as hipóteses $\mathrm{H} 1$ e $\mathrm{H} 3$ da pesquisa. A percepção de qualidade foi maior em cenários com alta responsividade $(M=4,84)$ que em cenários com baixa responsividade $(M=3,57)$. Em relação ao efeito principal do preço, a percepção de qualidade, de acordo com três níveis, apresentou as seguintes médias: preço acima da média $(M=4,37)$; preço na média $(M=4,23)$ e preço abaixo da média da concorrência $(\mathrm{M}=3,99)$. Os resultados dos testes Post-hoc LSD indicaram que a percepção de qualidade no caso do alto preço foi significativamente diferente $(\mathrm{p}<0,05)$ em relação ao preço abaixo da média. Não foi encontrada diferença significativa entre níveis abaixo e acima da média em relação ao preço na média $(\mathrm{p}>0,05)$.

Além disso, foi encontrado efeito de interação das variáveis preço e responsividade na percepção de qualidade $(\mathrm{F}(2,139)=2,90 ; \mathrm{p}<0,05)$, também entre as variáveis preço e CCP $(\mathrm{F}(2,139)$ $=3,49 ; \mathrm{p}<0,05)$, e entre as variáveis responsividade e $\mathrm{CCP}(\mathrm{F}(1,139)=6,02 ; \mathrm{p}<0,05)$.

As interações foram novamente examinadas pelos testes Post-hoc LSD, com a realização de sub-grupos. Os resultados demonstram novamente que, entre sujeitos expostos a cenários com baixa responsividade, as médias da qualidade percebida para os diferentes níveis de preço não são diferentes $(\mathrm{M}=3,50, \mathrm{M}=3,46$, e $\mathrm{M}=3,75$ para abaixo da média, na média e acima da média de preço, respectivamente, $\mathrm{p}>0,05)$. As médias são diferentes apenas entre sujeitos expostos a cenários com alta responsividade ( $M=4,48, M=5,06$, e $M=4,99$ para abaixo da média, na média e acima da média de preço, respectivamente). Entre esses, a qualidade foi percebida como significativamente diferente entre os sujeitos expostos a preços acima da média e os expostos a preços abaixo da média $(\mathrm{p}<0,01)$, e entre os expostos a preços na média e abaixo da média $(\mathrm{p}<0,01)$. Já o preço na média da concorrência não foi encontrado como significativamente diferente se comparado ao grupo exposto a preços acima da média $(\mathrm{p}=0,70)$. Os resultados desses testes são representados na Figura 3.

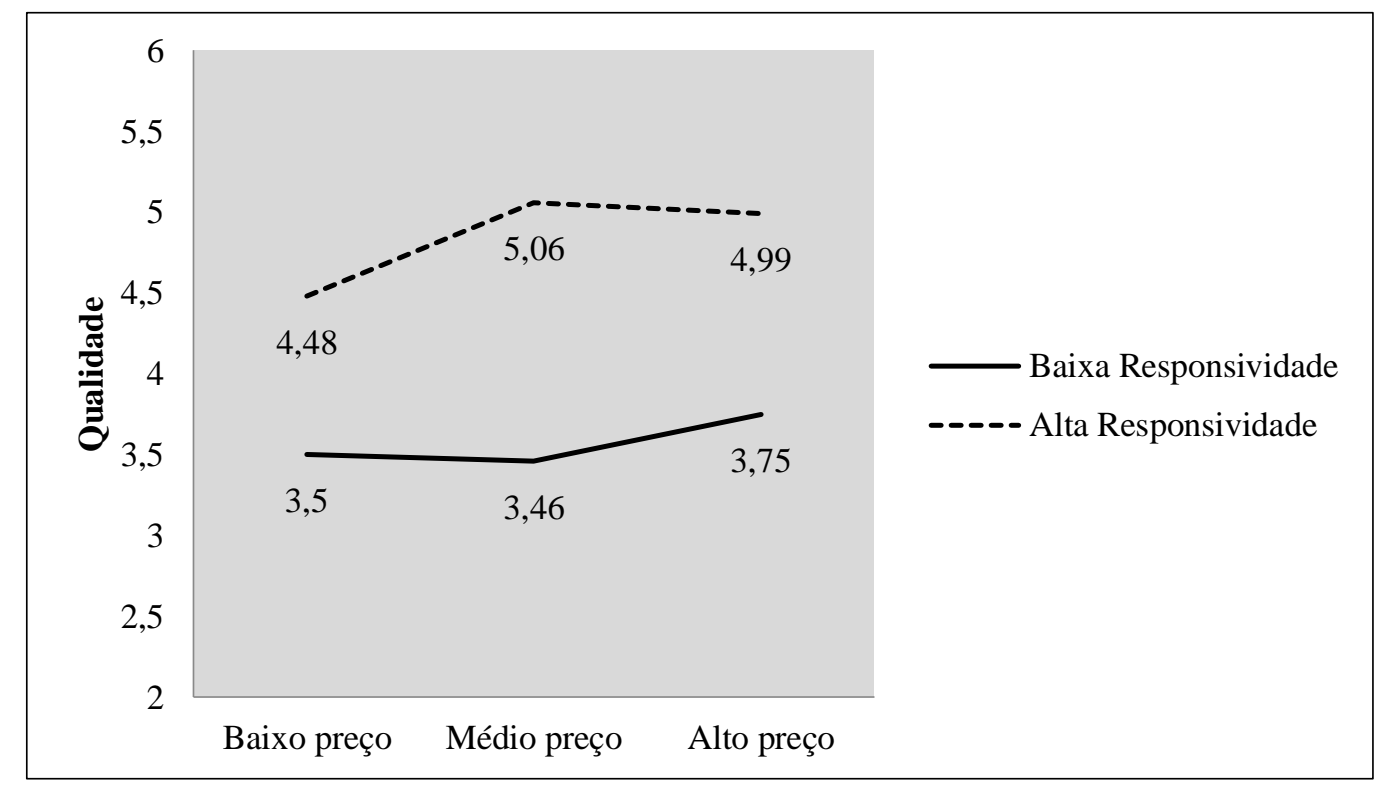

Figura 3. Efeito Interativo entre Preço e Responsividade na Qualidade Percebida.

Para a análise da interação entre responsividade e CCP, o banco de dados foi separado em dois grupos, com alto CCP e com baixo CCP. As médias da qualidade percebida no grupo com alto CCP entre os dois níveis de responsividade foram significativas $(F(1,76)=88,26 ; p<0,01)$. Igualmente, no grupo com baixo CCP, os dois níveis de responsividade também foram significativos $(F(1,84)=37,71$; 
$\mathrm{p}<$ 0,01). Dessa forma, não foi confirmada a hipótese $\mathrm{H} 5$, que propunha que a relação entre responsividade e qualidade percebida seria maior no grupo com baixo CCP. Porém, a sinalização parece mais forte entre os indivíduos expostos a alto CCP.

Para a análise da interação entre preço e CCP, também foi mantida a separação do banco de dados em dois grupos. No grupo com baixo CCP, as médias da percepção de qualidade, segundo o nível do preço, foram as seguintes: preço acima da média $(M=4,58)$, preço na média $(M=4,10)$ e preço abaixo da média $(\mathrm{M}=3,91)$. No grupo com alto $\mathrm{CCP}$, as médias da percepção de qualidade segundo o nível do preço foram as seguintes: preço acima da média $(M=4,16)$, preço na média $(M=$ 4,38) e preço abaixo da média $(\mathrm{M}=4,07)$. Os testes Post-hoc LSD demonstram que, entre sujeitos expostos a baixo CCP, as médias da qualidade percebida para os diferentes níveis de preço são significativamente diferentes entre o nível mais alto do preço e os outros dois níveis (baixo e médio preço, $\mathrm{p}<0,05)$. As médias não são diferentes entre sujeitos expostos ao nível mais baixo de preço e sujeitos expostos ao preço na média $(\mathrm{p}=0,41)$. Já no grupo com alto $\mathrm{CCP}$, as médias da percepção de qualidade não apresentaram diferenças significativas com relação aos diferentes níveis de preço ( $>0,05$ ). Dessa forma, foi suportada a hipótese $\mathrm{H} 4$, que propõe que a relação entre preço e qualidade seria mais forte entre sujeitos expostos a cenários com baixo CCP, quando comparados aos expostos a alto CCP. Os resultados desses testes são representados na Figura 4.

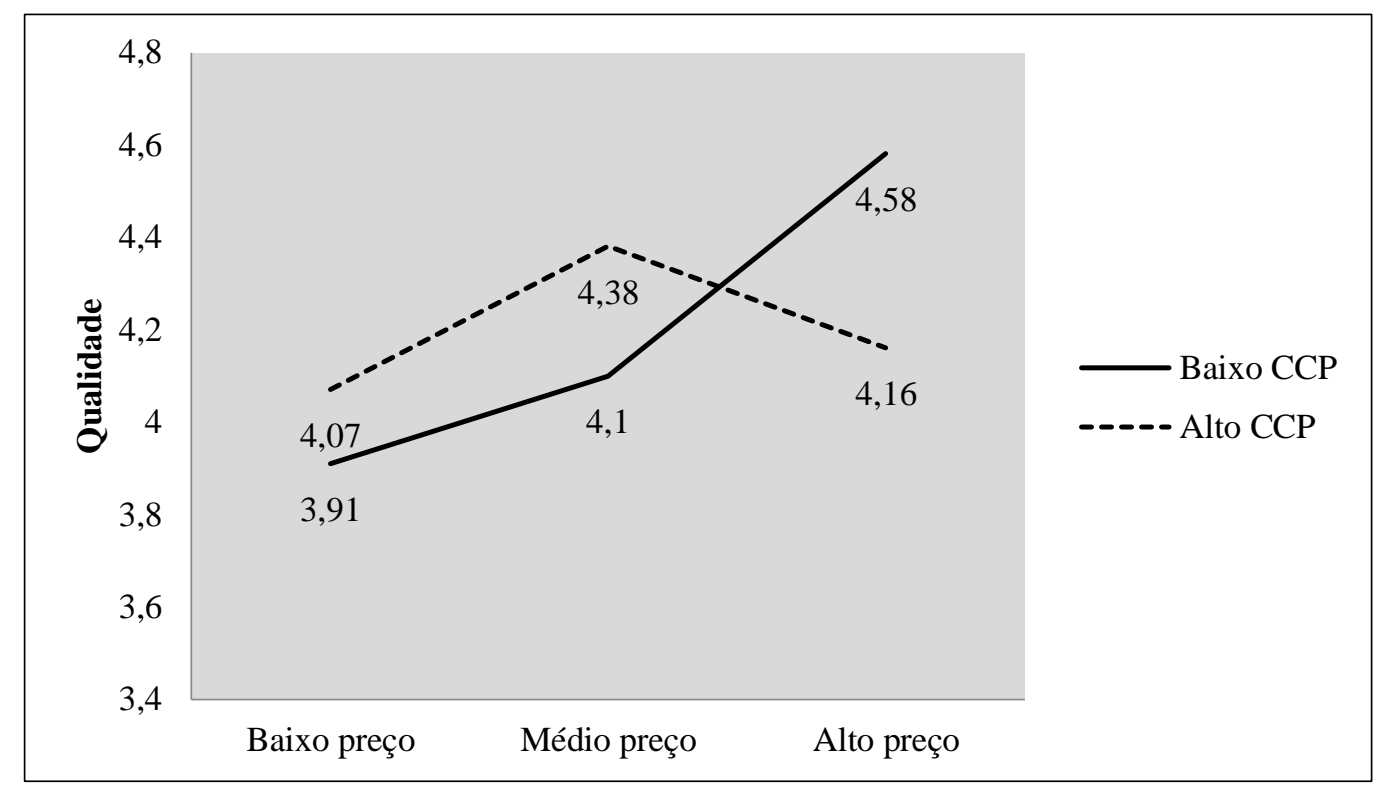

Figura 4. Efeito Interativo entre CCP e Preço na Qualidade Percebida.

\section{Moderação do "Esquema”}

Procedeu-se, então, ao teste sobre a moderação da variável esquema na relação entre preço e qualidade percebida. O possível efeito moderador da variável esquema nessa relação foi testado através do macro MODPROBE, desenvolvido por Hayes e Matthes (2009).

Os resultados obtidos confirmaram o efeito moderador da variável esquema no modelo $\left(\mathrm{b}_{3}=\right.$ $0,1817, \mathrm{t}=2,3085, \mathrm{p}=0,021)$. O efeito do preço na qualidade é significativo na medida em que os valores do esquema aumentam, confirmando, dessa forma, a hipótese $\mathrm{H} 2$, a qual sugere que, quanto maior for a aceitação do indivíduo no esquema preço-qualidade, maior será o impacto do preço na qualidade percebida.

Para a análise do resultado, foi transformada a variável intervalar esquema preço-qualidade em uma variável dicotômica (baixo e alto esquema), a partir da média da escala (abaixo da média = baixo esquema; acima da média = alto esquema). Posteriormente, o banco de dados foi dividido em dois grupos. No grupo com baixo esquema, as médias da percepção de qualidade segundo o nível do 
preço foram as seguintes: preço acima da média $(M=4,15)$, preço na média $(M=4,26)$ e preço abaixo da média $(M=4,10)$. No grupo com alto esquema, as médias da percepção de qualidade segundo o nível do preço foram as seguintes: preço acima da média $(\mathrm{M}=4,50)$, preço na média $(\mathrm{M}=4,32) \mathrm{e}$ preço abaixo da média $(\mathrm{M}=3,93)$.

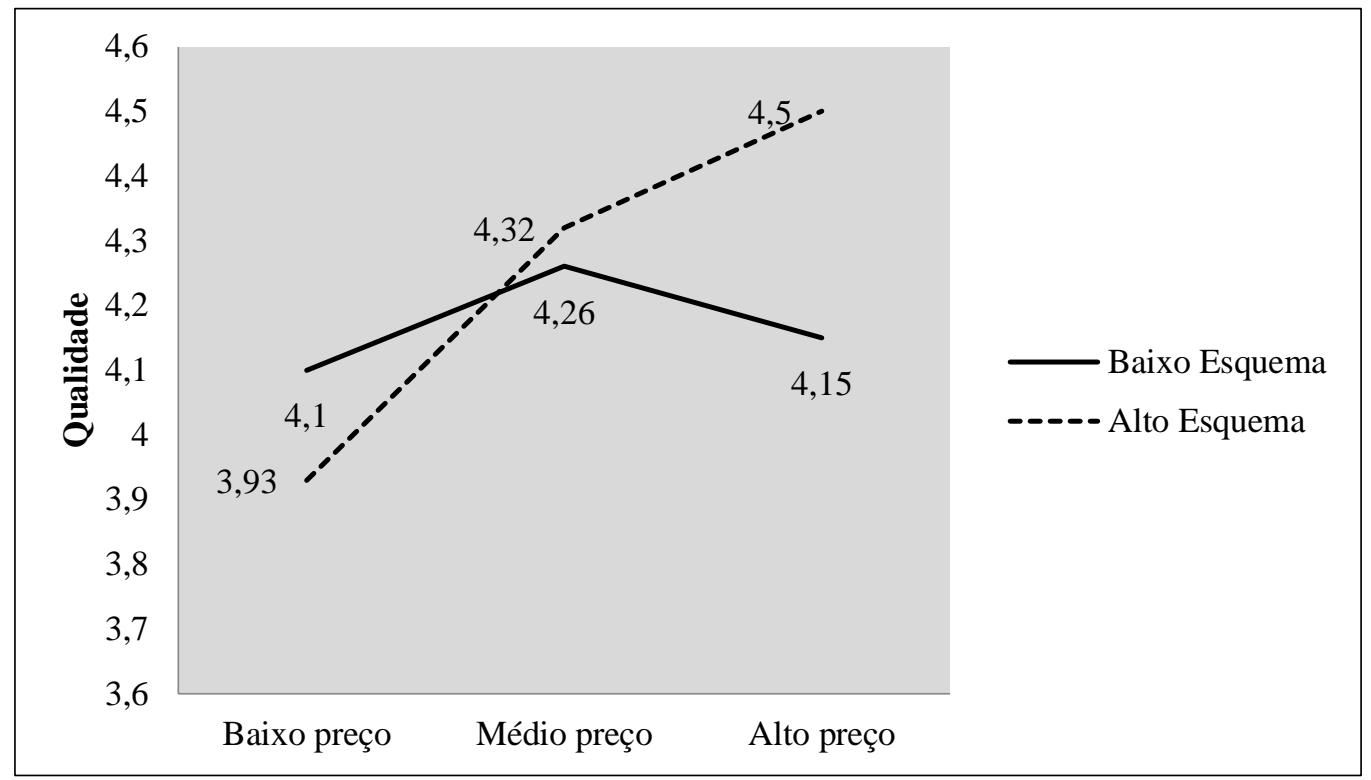

Figura 5. Efeito Interativo entre Esquema e Preço na Qualidade Percebida.

Os testes Post-hoc LSD demonstram que, entre sujeitos com alto esquema, as médias da qualidade percebida para os diferentes níveis de preço são significativamente diferentes entre o nível mais alto e o nível mais baixo $(\mathrm{p}<0,05)$. As médias não são diferentes comparando-se os sujeitos nesses dois níveis com os sujeitos expostos a cenários com preço na média ( $p>0,05$ ); enquanto que, no grupo com baixo esquema, as médias da percepção de qualidade não apresentaram diferenças significativas $(\mathrm{p}>0,05)$. Os resultados desses testes são apresentados na Figura 5.

Ressalta-se que os resultados completos dos testes post hoc LSD, desse e do primeiro experimento, não foram trazidos em sua totalidade por uma questão de espaço, mas estão disponíveis junto aos autores deste artigo. Ainda foram realizados testes post hoc Tukey em que foram encontrados resultados semelhantes aos descritos aqui.

\section{Discussão}

Os resultados do estudo 2 corroboram os achados do primeiro experimento. As hipóteses H1 e H3 foram novamente confirmadas, indicando que o preço e a responsividade atuam como sinalizadores de qualidade. Em relação à interação, foi novamente encontrado que as diferenças na percepção de qualidade, segundo os diferentes níveis de preço, são somente significativas no caso de alta responsividade, e não no caso de baixa responsividade.

Além disso, os resultados confirmam o efeito moderador da variável CCP na relação entre preço e qualidade percebida. Segundo a base teórica, a relação entre as variáveis seria maior entre sujeitos com baixo CCP que entre sujeitos com alto CCP. Foi encontrado que, no grupo com baixo CCP, a percepção de qualidade foi significativamente diferente entre o nível de preço superior à concorrência e os outros dois níveis de preço (médio e inferior à concorrência), mas não entre o nível de preço médio e o nível de preço inferior à concorrência. Enquanto que, no grupo com alto CCP, não foi encontrado o efeito sinalizador significativo do preço. Dessa forma, foi confirmada a hipótese H4.

No caso da responsividade, a relação foi significativa nos dois casos (com alto e baixo CCP), não existindo efeito de moderação da variável CCP. Assim, não foi suportada a hipótese H5 do 
trabalho, a qual apontava que a relação seria mais forte no caso de baixo CCP. Em relação a esse resultado, pode-se novamente ressaltar a importância da responsividade como fator determinante da qualidade dos serviços (Parasuraman et al., 1985). Devido à importância crucial dessa variável no setor de serviço, seria mais difícil encontrar um fator que modere o seu efeito na percepção de qualidade do serviço.

Em relação ao esquema preço-qualidade, confirmou-se o efeito moderador dessa variável na relação entre preço e qualidade percebida. $\mathrm{O}$ efeito do preço na qualidade é significativo quando as crenças no esquema aumentam. Em outras palavras, quanto maior é a aceitação do indivíduo do esquema preço-qualidade, maior é o impacto da sinalização do preço na qualidade percebida. Portanto, o resultado é consistente com o proposto por alguns autores (Lichtenstein \& Burton, 1989; Rao \& Monroe, 1988) sobre a existência de fatores (por exemplo, características individuais) que podem afetar a relação entre preço e qualidade. Dessa maneira, confirma-se a hipótese H2.

\section{Considerações Finais e Contribuições Teóricas e Gerenciais}

Este trabalho apresenta evidências empíricas dos efeitos da sinalização de qualidade através das variáveis preço e responsividade. Uma das contribuições foi investigar o efeito dessas variáveis na percepção de qualidade, utilizando um contexto de serviço - de reserva de hotel. Os resultados demonstram que as variáveis preço e responsividade influenciam a percepção do cliente sobre a qualidade nos serviços a serem comprados.

No caso do preço, seu efeito sinalizador amplamente demonstrado no setor de produtos pode ser estendido no setor de serviços, através dos resultados empíricos encontrados neste trabalho. Em ambos os estudos, foi encontrado o efeito sinalizador do preço na qualidade percebida. Estes resultados confirmam o efeito sinalizador do preço, mesmo não afetando na qualidade percebida exatamente da maneira esperada (ou seja, de forma perfeitamente linear de acordo com os três níveis de preço). Isso parece sugerir a existência de outros fatores que poderiam estar afetando a relação entre preço e qualidade percebida como, por exemplo, diferenças individuais.

Em relação à responsividade, foi encontrado que a percepção de qualidade é superior quando a percepção de responsividade é maior e vice-versa. Como foi explicado previamente, na revisão da literatura, a responsividade representa uma dimensão utilizada pelos consumidores para avaliar os serviços. Sua importância como fator chave da qualidade foi ressaltada por vários autores (e.g. Johnston, 1995; Malhotra et al., 1994; Parasuraman, Zeithaml, \& Berry, 1988). Os resultados encontrados em ambos os estudos constituem uma contribuição original deste trabalho, pois confirmam o papel fundamental da responsividade como sinalizadora de qualidade. Dessa forma, o investimento em responsividade se converte em uma importante ferramenta a ser gerenciada pelas empresas prestadoras de serviço.

Outra contribuição original deste trabalho é ter identificado o controle comportamental percebido (CCP) como uma moderadora dos efeitos da sinalização. Com base na literatura consultada, o CCP pode moderar a relação entre as variáveis sinalizadoras e a percepção de qualidade. Os resultados do estudo confirmam o efeito moderador do CCP no caso do preço, em que o efeito sinalizador do preço foi significativo em caso de baixo CCP, enquanto que não foi encontrado efeito sinalizador do preço no caso de alto CCP. Isso significa que os indivíduos com baixo CCP são mais suscetíveis de ponderar o preço como sinalizador na hora de avaliar a qualidade dos serviços do que os com alto CCP.

Contrariamente ao que era previsto, o CCP não moderou o efeito sinalizador da responsividade. $\mathrm{O}$ efeito da responsividade na percepção de qualidade foi significativo tanto com baixo CCP quanto com alto CCP. Estes resultados podem ser consequência da função determinante da responsividade na qualidade do serviço, como dito anteriormente. 
Finalmente, neste trabalho, foi examinado outro fator moderador da relação entre preço e qualidade percebida, o esquema preço-qualidade. Segundo Lichtenstein e Burton (1989), essa relação pode ser afetada pelas diferenças dos indivíduos, neste caso, pela crença no esquema preço-qualidade. De acordo com os resultados encontrados, a crença no esquema preço-qualidade afeta de forma significativa o efeito do preço na percepção de qualidade, ou seja, quando maior é a crença no esquema preço-qualidade maior é o efeito do preço na qualidade percebida.

Como contribuição gerencial, embora estudos empíricos tenham versado sobre avaliações da qualidade dos serviços e na satisfação dos consumidores, poucos têm examinado como essas avaliações são influenciadas por elementos de sinalização de qualidade utilizados pelas empresas. Os resultados dessa pesquisa permitem às empresas de serviços entender melhor o efeito de suas táticas de sinalização de qualidade, particularmente os elementos estudados aqui, preço e responsividade, possibilitando que aumentem a qualidade percebida do serviço, através desses elementos. Faz parte desse entendimento o fato de que os resultados encontrados corroborem a ideia de que os sinais referentes ao preço só são percebidos por aqueles consumidores motivados a desempenhar um esforço cognitivo na sua tomada de decisão, isso é, os que são menos confiantes em suas capacidades de executar tal decisão (i.e., com menor controle comportamento percebido), e também para aqueles que aceitam mais o esquema entre preço/qualidade. Já para aqueles que são mais confiantes e pensam ser eficazes na escolha do serviço (i.e., com maior controle comportamento percebido) e para aqueles que não possuem entre suas crenças o esquema preço/qualidade, isto é, são menos propensos a usar o preço como sinalizador da qualidade, preço não atua como um sinalizador de qualidade forte. Nesses casos, as empresas poderiam utilizar outros sinais, como a responsividade trazida nessa pesquisa.

Como contribuição teórica original, tem-se a aplicação da sinalização de qualidade no setor de serviços, considerando-se as peculiaridades desse setor. Nesse sentido, destaca-se o exame do elemento responsividade, entre os estudados, como o mais particular a esse setor. Até o presente momento, não foram encontrados trabalhos que busquem associar essas duas vertentes de pesquisa - a teoria da sinalização e os elementos do ambiente de serviços, com exceção do ensaio teórico de Koetz, Santos e Kopschina (2009). Sem dúvida, essa será uma contribuição importante para a área de conhecimento de marketing.

\section{Limitações e sugestões de pesquisas futuras}

As contribuições trazidas pelo estudo aqui apresentado devem ser ponderadas pelas restrições que o cercaram. Embora se saiba que o laboratório oferece variação controlada e que esta é a base do conhecimento científico empírico (Falk \& Heckman, 2009), e que quando o objetivo é testar proposições teóricas, o experimento laboratorial é o mais indicado, visto que promove um maior controle sobre as variáveis, que é base do conhecimento científico empírico (Falk \& Heckman, 2009) e possibilita uma distribuição aleatória dos participantes pelos grupos de tratamento (Calder, Phillips, \& Tybout, 1981), a primeira limitação refere-se à realização dos experimentos em ambiente laboratorial, com cenários descritivos que, apesar de amplamente utilizados (Hess, Ganesan, \& Klein, 2003; McCollough, Berry, \& Yadav, 2000), carregam certo grau de artificialidade. Além disso, mesmo que os cenários utilizados tenham sido produzidos com o objetivo de gerar estímulos fidedignos e o mais próximos possível da realidade, as situações descritas são hipotéticas e os entrevistados podem não exercer o mesmo comportamento no caso de experiências reais de consumo. Da mesma forma, nessa pesquisa, manipularam-se os elementos de sinalização através de uma página de website. Em uma situação real de compra, é possível que a qualidade do site, a navegabilidade e outros aspectos afetem a análise dos compradores potenciais e também a influência de outros sinais utilizados pela empresa, como, por exemplo, o preço. Nesse sentido, recomenda-se que pesquisas futuras manipulem esses elementos em outros contextos (e.g., em uma peça de comunicação da empresa) e também apliquem estudos não experimentais (survey ou logitudinal) e experimentos de campo como complementação ao presente trabalho.

Neste artigo, os dois experimentos foram conduzidos com amostras não probabilísticas, compostas de estudantes de graduação. Mesmo que amostras homogêneas sejam adequadas para gerar 
maior validade interna em experimentos (Calder et al., 1981), os resultados não podem ser generalizados para todo e qualquer consumidor. Outra limitação a ser citada com relação à validade externa, refere-se à especificidade do cenário utilizado, envolvendo reserva de hotéis, que foi utilizado em ambos os estudos. A fim de se validar os resultados encontrados, sugere-se a aplicação da pesquisa em outros setores/serviços e em outras populações.

Ainda, os dois estudos apresentados aqui tiveram amostras relativamente pequenas, similar a alguns experimentos publicados em periódicos científicos de referência (e.g., Rao et al., 1999; Teas \& Agarwal, 2000; Wertenbroch \& Dhar, 2000). Estudos futuros poderão ser beneficiados por amostras maiores, uma vez que, para a mesma magnitude de efeito, estudos com amostras maiores oferecem um valor de diagnóstico maior (Brinberg, Lynch, \& Sawyer, 1992).

Em relação aos elementos de sinalização utilizados, nesse primeiro momento, apenas dois preço e responsividade - foram investigados, por se tratar de um esforço inicial de pesquisa para se entender a sinalização de qualidade no contexto de serviços. Sugere-se que futuras pesquisas investiguem outras variáveis sinalizadoras de qualidade, incluindo variáveis específicas do setor de serviços, como o investimento no ambiente (servicescape) - que está associado aos tangíveis de Parasuraman et al. (1988) - e investimento nos funcionários (p.ex., a contratação de um chef de cozinha renomado em um restaurante), seguindo as recomendações de Koetz et al. (2009). Outra possibilidade de investigação são as características do website, como por exemplo, tempo para download e segurança nas transações, como potenciais sinais da qualidade dos produtos ou serviços vendidos através do site, seguindo a linha de trabalho de Wells, Valacich e Hess (2011).

Poderia ser questionado o fato de se abordar apenas uma variável da SERVQUAL, não utilizando todas as dimensões da mesma. Nesse sentido, é importante ressaltar que a variável responsividade, apesar de ser considerada uma dimensão da SERVQUAL, não está nessa pesquisa a serviço da SERVQUAL, isso é, para avaliar a qualidade de serviços, conforme proposto por Parasuraman e colegas (1988). Responsividade está sendo considerada um elemento de sinalização, por estar em sintonia com os pressupostos da teoria de sinalização identificados por Kirmani e Rao (2000), como, por exemplo, o consumidor ter uma ideia, antes de efetuar a compra, do montante investido na ação de sinalização, o qual deve ser passível de comparação com os investimentos realizados pelos concorrentes. Note que outras pesquisas têm abordado, de forma mais particular e isolada, apenas uma das dimensões da SERVQUAL, como por exemplo, a confiabilidade dos funcionários (e.g., Sharma, 1990; Swan, Bowers, \& Richardson, 1999), os tangíveis (e.g., Baker, Dhruv, \& Parasuraman, 1994; Berry, Wall, \& Carbone, 2006; Bitner, 1990; Reimer \& Kuehn, 2005), a empatia dos funcionários (Varca, 2009; Wieseke, Geigenmüller, \& Kraus, 2012), e a responsividade (e.g., Hocutt, 1998; Naylor \& Frank, 2000, Richins, 1983).

Com relação ao efeito do preço, especificamente, cabe ressaltar que, conforme Mitchel e Greatorex (1989), a importância desse fator na percepção de qualidade pode ser atenuada pelo conhecimento de outros atributos relativos ao prestador do serviço, como, por exemplo, a localização do hotel ou sua reputação. Nesse sentido, sugere-se que futuras pesquisas investiguem o impacto desse fator na presença de outros atributos da empresa avaliada.

Por fim, recomenda-se ainda que, de forma semelhante a este trabalho, pesquisas examinem o efeito do uso de mais de uma variável sinalizadora de qualidade simultaneamente. Segundo Kirmani e Rao (2000), a combinação de sinais de distintas categorias seria mais apropriada que utilizar sinais de somente uma, assim as propriedades seriam complementadas e não somente duplicadas.

\section{Notas}

\footnotetext{
${ }^{1}$ Em uma ampla investigação na literatura existente, encontraram-se três exceções: Toncar et al. (2010), que testam o efeito do preço esperado na avaliação de qualidade do serviço; Erevelles et al. (2001), que examinam o efeito do preço e da garantia na percepção de qualidade em bens duráveis e serviços; e o ensaio teórico de Koetz et al. (2009).
} 
${ }^{2}$ Os preços utilizados surgiram de uma investigação realizada pelas autoras sobre preços oferecidos no mercado de hotéis três estrelas em uma cidade dos Estados Unidos, e foram percebidos como adequados na fase de pré-testes desse estudo.

\section{Referências}

Ajzen, I. (1991). The theory of planned behavior. Organizational Behavior and Human Decision Processes, 50(2), 179-211. doi: 10.1016/0749-5978(91)90020-T

Albarracin, D., \& Wyer, R. S., Jr. (2000). The cognitive impact of past behavior: influences on beliefs, attitudes, and future behavioral decisions. Journal of Personality and Social Psychology, 79(1), 5-22. doi: 10.1037//0022-3314.79.1.5

Baker, J., Dhruv, G., \& Parasuraman, A. (1994). The influence of store environment on quality inferences and store image. Journal of the Academy of Marketing Science, 22(4), 328-339. doi: $10.1177 / 0092070394224002$

Berry, L. L., Wall, E. A., \& Carbone, L. P. (2006). Service clues and customer assessment of the service experience: lessons from marketing. Academy of Management Perspectives, 20(2), 4357. doi: 10.5465/AMP.2006.20591004

Bitner, M. J. (1990). Evaluating service encounters: the effects of physical surroundings and employee Responses. Journal of Marketing, 54(2), 69-82.

Bitner, M. J., \& Hubbert, A. R. (1994). Encounter satisfaction versus overall satisfaction versus quality. In R. Rust \& R. Oliver (Orgs.), Service quality: new directions in theory and practice (pp. 72-94). Thousand Oaks: Sage Publications.

Boulding, W., \& Kirmani, A. (1993). A consumer-side experimental examination of signaling theory: do consumers perceive warranties as signals of quality? Journal of Consumer Research, 20(1), 111-123. doi: 10.1086/209337

Brinberg, D., Lynch, L., \& Sawyer, A. (1992). Hypothesized and confounded explanations in theory tests: a Bayesian analysis. Journal of Consumer Research, 19(2), 139-154.

Calder, B. J, Phillips, L. W., \& Tybout, A. M. (1981). Designing research for application. Journal of Consumer Research, 8(2), 197-207. doi: 10.1086/208856

Chaiken, S. (1980). Heuristic versus systematic information processing and the use of source versus message cues in persuasion. Journal of Personality and Social Psychology, 39(5), 752-766. doi: 10.1037/0022-3514.39.5.752

Connelly, B. L., Certo, S. T., Ireland, R. D., \& Reutzel, C. R. (2011). Signaling theory: a review and assessment. Journal of Management, 37(1), 39-67. doi: 10.1177/0149206310388419

Erevelles, S., Roy, A., \& Yip, L. S. C. (2001). The universality of the signal theory for product and services. Journal of Business Research, 52(2), 175-187. doi: 10.1016/S0148-2963(99)00069-7

Falk, A., \& Heckman, J. J. (2009). Lab experiments are a major source of knowledge in the Social Sciences. Science, 326(5952), 535-538. doi: 10.1126/science.1168244

Gerstner, E. (1985). Do higher prices signal higher quality? Journal of Marketing Research, 22(2), 209215.

Grönroos, C. (2003). Service management and marketing (2nd ed.). Chichester: Wiley. 
Hair, J. F., Jr., Babin, B., Money, A. H., \& Samouel, P. (2005). Fundamentos de métodos de pesquisa em administração. Porto Alegre: Bookman.

Hayes, A. F., \& Matthes, J. (2009). Computational procedures for probing interactions in OLS and logistic regression: SPSS and SAS implementations. Behavior Research Methods, 41(3), 924936. doi: 10.3758/BRM.41.3.924

Hess, R. L., Jr., Ganesan, S., \& Klein, N. M. (2003). Service failure and recovery: the impact of relationship factors on customer satisfaction. Journal of the Academy of Marketing Science, 31(2), 127-145. doi: 10.1177/0092070302250898

Hocutt, M. A. (1998). The impact of employee empowerment on the quallity of a service recovery effort. Journal of Quality Management, 3(1), 117-132. doi: 10.1016/S1084-8568(99)80107-2

Johnston, R. (1995). The determinants of service quality: satisfiers and dissatisfiers. International Journal of Service Industry Management, 6(5), 53-71. doi: 10.1108/09564239510101536

Kelley, H. H. (1973). The process of causal attribution. American Psychologist, 28(2), 107-128. doi: $10.1037 / \mathrm{h} 0034225$

Kidwell, B., \& Jewell, R. D. (2010). The motivational impact of perceived control on behavioral intentions. Journal of Applied Social Psychology, 40(9), 2407-2433. doi: 10.1111/j.15591816.2010.00664.x

Kirmani, A., \& Rao, A. R. (2000). No pain, no gain: a critical review of the literature on signaling unobservable product quality. Journal of Marketing, 64(2), 66-79. doi: 10.1509/jmkg.64.2.66.18000

Kirmani, A., \& Wright, P. (1989). Money talks: perceived advertising expense and expected product quality. Journal of Consumer Research, 16(3), 344-353. doi: 10.1086/209220

Koetz, C. I., Santos, C. P., \& Kopschina, L. C. Y. A. (2009). A sinalização da qualidade nos serviços. Revista de Gestão, 16(3), 81-97.

Kupiec, B., \& Revell, B. (2001). Measuring consumer quality judgements. British Food Journal, 103(1), 7-22. doi: 10.1108/00070700110382911

Leavitt, H. J. (1954). A note on some experimental findings about the meaning of price. Journal of Business, 27(3), 205-210.

Lichtenstein, D. R., \& Burton, S. (1989). The relationship between perceived and objective price quality. Journal of Marketing Research, 26(4), 429-443.

Lichtenstein, D. R., Ridgway, N. M., \& Netemeyer, R. G. (1993). Price perceptions and consumer shopping behavior: a field study. Journal of Marketing Research, 30(2), 234-245. doi: $10.2307 / 3172830$

Lutz, R. (1986). Quality is as quality does: an attitudinal perspective on consumer quality judgments. Proceedings in the international conference in Cambridge, Cambridge, MA, USA.

Malhotra, N. K., Ulgado, F. M., Agarwal, J., \& Baalbaki, I. B. (1994). International services marketing: a comparative evaluation of the dimensions of service quality between developed and developing countries. International Marketing Review, 11(2), 5-15. doi: $10.1108 / 02651339410061937$

McCollough, M. A., Berry, L. L., \& Yadav, M. S. (2000). An empirical investigation of customer satisfaction after service failure and recovery. Journal of Service Research, 3(2), 121-137. doi: $10.1177 / 109467050032002$ 
Mitchel, V.-W., \& Greatorex, M. (1989). Risk reducing strategies used in the purchase of wine in the UK. European Journal of Marketing, 23(9), 31-46. doi: 10.1108/EUM0000000000589

Monroe, K. B., \& Krishnan, R. (1983). A procedure for integrating outcomes across studies. Advances in Consumer Research, 10(1), 503-508.

Naylor, G., \& Frank, K. E. (2000). The impact of retail sales force responsiveness on consumers' perceptions of value. Journal of Service Marketing, 14(4), 310-322. doi: $10.1108 / 08876040010334529$

Nelson, P. (1974). Advertising as Information. Journal of Political Economy, 82(4), 729-754.

Olson, J. C. (1977). Price as an informational cue: effects in product evaluation. In A. G. Woodside, J. N. Sheth, \& P. D. Bennett (Eds.), Consumer and Industrial Buying Behavior (pp. 267-286). New York: Elsevier.

Ouellette, J. A., \& Wood, W. (1998). Habit and intention in everyday life: the multiple processes by which past behavior predicts future behavior. Psychological Bulletin, 124(1), 54-74. doi: 10.1037//0033-2909.124.1.54

Parasuraman, A., Zeithaml, V. A., \& Berry, L. L. (1985). A conceptual model of service quality and its implications for future research. Journal of Marketing, 49(4), 41-50. doi: 10.2307/1251430

Parasuraman, A., Zeithaml, V. A., \& Berry, L. L. (1988). SERVQUAL: a multiple-item scale for measuring consumer perception of service quality. Journal of Retailing, 64(1), 12-40.

Park, C. W., \& Mittal, B. (1985). A theory of involvement in consumer behavior: problems and issues. In J. Sheth (Org.), Research in consumer behavior (pp. 201-231). Greenwich: JAI Press.

Rao, A. R., \& Monroe, K. B. (1988). The moderating effect of prior knowledge on cue utilization in product evaluations. Journal of Consumer Research, 15(2), 253-264. doi: 10.1086/209162

Rao, A. R., Qu, L., \& Ruekert, R. W. (1999). Signaling unobservable product quality through a brand ally. Journal of Marketing Research, 36(2), 258-268.

Reimer, A., \& Kuehn, R. (2005). The impact servicescape on quality perception. European Journal of Marketing, 39(7/8), 785-808. doi: 10.1108/03090560510601761

Richins, M. L. (1983). Negative word-of-mouth by dissatisfied consumers: a pilot study. Journal of Marketing, 47(1), 68-78.

San Martín, S., \& Camarero, C. (2005). Consumer reactions to firm signals in asymmetric relationships. Journal of Service Research, 8(1), 79-97. doi: 10.1177/1094670504273967

Sawyer, A. G. (1975). Demand artifacts in laboratory experiments in consumer research. Journal of Consumer Research, 1(4), 20-30. doi: 10.1086/208604

Sharma, A. (1990). The persuasive effect of salesperson credibility: conceptual and empirical examination. Journal of Personal Selling and Sales Management, 10(4), 71-80. doi: $10.1080 / 08853134.1990 .10753850$

Swan, J. E., Bowers, M. R., Richardson, L. D. (1999). Customer trust in the salesperson: an integrative review and meta-analysis of the empirical literature. Journal of Business Research, 44(2), 93107. doi: 10.1016/S0148-2963(97)00244-0

Taylor, S. E. (1975). On inferring one's attitudes from one's behavior: some delimiting conditions. Journal of Personality and Social Psychology, 31(1), 126-131. doi: 10.1037/h0076246 
Teas, R. K., \& Agarwal, S. (2000). The effects of extrinsic product cues on consumers' perceptions of quality, sacrifice, and value. Journal of the Academy of Marketing Science, 28(2), 278- 290. doi: $10.1177 / 0092070300282008$.

Tellis, G. J., \& Wernerfelt, B. (1987). Competitive price and quality under asymmetric information. Marketing Science, 6(3), 240-253. doi: 10.1287/mksc.6.3.240

Toncar, M. F., Alon, I., \& Misati, E. (2010). The importance of meeting price expectations: linking price to service quality. Journal of Product \& Brand Management, 19(4), 295-305. doi: $10.1108 / 10610421011059612$

Varca, P. E. (2009). Emotional empathy and front line employees: does it make sense to care about the customer? Journal of Services Marketing, 23(1), 51-56. doi: 10.1108/08876040910933093

Veeck, A., \& Burns, A. C. (1995). An investigation of the use of price-quality schema by urban Chinese consumers. Advances in Consumer Research, 22(1), 297-302.

Walker, R. H., \& Johnson, L. W. (2009). Signaling intrinsic service quality and value via accreditation and certification. Managing Service Quality, 19(1), 85-105. doi: 10.1108/09604520910926827

Wells, J. D., Valacich, J. S., \& Hess, T. J. (2011). What signals are you sending? How website quality influences perceptions of product quality and purchase intentions. MIS Quarterly, 35(2), 373396.

Wertenbroch, K., \& Dhar, R. (2000). Consumer choice between hedonic and utilitarian goods. Journal of Marketing Research, 37(1), 60-71.

Wieseke, J., Gergenmüller, A., \& Kraus, F. (2012). On the role of empathy in customer-employee interactions. Journal of Service Research, 15(3), 316-331. doi: 10.1177/1094670512439743

Zeithaml, V. A. (1988). Consumer perception of price, quality, and value: a means-end model and synthesis of evidence. Journal of Marketing, 52(3), 2-22.

Zeithaml, V. A., \& Bitner, M. J. (2003). Marketing de serviços: a empresa com foco no cliente (2a ed.). Porto Alegre: Bookman. 